\title{
Synergistic Effect of Indomethacin with Adriamycin and Cisplatin on Tumor Growth
}

\author{
Kenji Hattori ${ }^{a}$ Ryo Matsushita, ${ }^{b}$ Kazuko Kimura, ${ }^{b}$ Yoshihiro Abe, ${ }^{a}$ and Emi Nakashima ${ }^{*}, c$ \\ Department of Fundamental Experimental Pharmaco-Science, Kyoritsu College of Pharmacy, ${ }^{a}$ 1-5-30 Shibakoen, Minato- \\ ku, Tokyo, 105-8512 Japan, Department of International Pharmacy and Health Sciences, Graduate School of Natural \\ Science and Technology, Kanazawa University, ${ }^{b}$ 13-1 Takara-machi, Kanazawa, 920-0934 Japan, and Department of \\ Pharmaceutics, Kyoritsu College of Pharmacy, ${ }^{c}$ Tokyo, Japan. $\quad$ Received May 24, 2001; accepted July 18, 2001
}

In this study, we have examined the antitumor effect of combined administrations of indomethacin (IND) with chemotherapeutic drugs on tumor growth. Colon 26 clone 20 (C20) cells and monocyte chemotactant protein-1 (MCP-1) transfected $\mathrm{C20}$ cells $(\mathrm{C20} \beta \mathrm{A}-2-1)$ were used and these cells were inoculated into the footpad of BALB/c mice. At day 1 after tumor inoculation, treatment with $0.001 \%$ IND via the drinking water was commenced. At days 4, 6, and 8, adriamycin or cisplatin was administered intravenously at a dose of $5 \mathrm{mg} / \mathrm{kg} \mathrm{or} \mathrm{in-}$ traperitoneally at a dose of $2 \mathrm{mg} / \mathrm{kg}$, respectively. Although IND, adriamycin and cisplatin only partially reduced the growth of the $\mathrm{C20}$ tumors after treatment with each drug on its own, a marked synergistic effect was observed when they were given in combination. A synergistic effect between IND and cisplatin on C20 $\beta A-2-1$ was also observed. However, IND itself showed no suppression of C20 $\beta$ A-2-1 tumor growth. These results suggest that combination of indomethacin with chemotherapeutic drugs could be an effective form of cancer chemotherapy. The observed effects may be dependent on the expression of MCP-1.

Key words indomethacin; Colon 26; chemotherapy; adriamycin; cisplatin

Prostaglandins (PGs) are known to be one of the regulators of tumor growth and spread. ${ }^{1-3)}$ PGs facilitate tumor growth by suppressing the immune system ${ }^{4-6}$ while indomethacin (IND), an inhibitor of PG production, has been reported to suppress tumor growth in some animal tumor models, ${ }^{1-3,7-12)}$ and several reports have suggested that IND facilitates tumors. ${ }^{13-16)}$ Although the antitumor efficacy of IND remains controversial, Tanaka et al. reported that IND given to mice with large burdens of colon 26 alleviated the cachexia in these animals, resulting in an prolonged survival time, even although the tumor growth was promoted. ${ }^{17)}$ These findings suggest that IND may restore tumor-induced disorders in homeostasis. Several studies have been reported showing that IND exhibits synergistic effects with several other biological response-modifiers and chemotherapeutic drugs in transplanted tumor models. ${ }^{18-20)}$ We have shown that IND and bleomycin (BLM) exhibit a strong synergistic effect. ${ }^{21)}$ In this report, we carried out further investigations of a combination of IND with adriamycin (ADM) or cisplatin (CDDP), which have different potencies and sites of action compared with BLM.

Previously, we have shown that monocyte chemotactant protein-1 (MCP-1) acts synergistically with lipopolysaccharide (LPS) on tumor growth. ${ }^{22)}$ Therefore, we also examined the possibility that MCP-1 expression may influence the synergistic antitumor effects of IND and chemotherapeutic drugs.

\section{MATERIALS AND METHODS}

Materials IND was obtained from Wako Pure Chemical, Ind. (Tokyo, Japan), BLM and CDDP were purchased from Nihon Kayaku (Tokyo, Japan), ADM was purchased from Kyowa Hakko (Tokyo, Japan) and all other chemicals used were of reagent grade.

Mice Female BALB/c mice (8-weeks old) were obtained from Clea (Tokyo, Japan). They were maintained under spe- cific pathogen-free conditions and their body weight was measured twice a week between 9:00 and 11:00 a.m. All animal experiments were approved by the Institutional Animal Care and Use Committee and complied with the standards set out in the Guidelines for the Care and Use of Laboratory Animals on the Takara-machi Campus of Kanazawa University.

Cell Culture Clone $20(\mathrm{C} 20)$ is a subclone of the colon 26 adenocarcinoma cell line which induces severe cancer cachexia. We previously established a cell line from C20, transfected MCP-1, designated C20 $\beta \mathrm{A}-2-1{ }^{22)}$ These cell lines were grown as monolayer cultures in complete medium consisting of RPMI 1640 medium supplemented with $10 \%$ fetal bovine serum, $2 \mathrm{~mm}$ glutamine, 100 units $/ \mathrm{ml}$ penicillin $\mathrm{G}$, and $100 \mu \mathrm{g} / \mathrm{ml}$ streptomycin at $37^{\circ} \mathrm{C}$ with $5 \% \mathrm{CO}_{2}$.

Inoculation of Tumor Cells The adherent cells were collected after a brief period of trypsinization and counted. Nine-week-old female mice were inoculated in the footpad of the right hind limb with $1 \times 10^{5}$ tumor cells per mouse suspended in $0.04 \mathrm{ml}$ sterilized endotoxin-free PBS. The tumor size at the injected site was determined by measuring the footpad thickness with calipers. At day 1 after tumor inoculation, treatment with $0.001 \%$ IND via the drinking water was commenced. At days 4, 6, and 8, BLM and CDDP were administered intraperitoneally at a dose of $5 \mathrm{mg} / \mathrm{kg}$ and $2 \mathrm{mg} / \mathrm{kg}$, respectively. ADM was administered intravenously at a dose of $5 \mathrm{mg} / \mathrm{kg}$. The tumor incidence (number of mice with tumor/number of mice inoculated) referred to 14 and $21 \mathrm{~d}$ of treatment without IND or with IND, respectively. When BALB/c mice rejected $\mathrm{C} 20$ or $\mathrm{C} 20 \beta \mathrm{A}-2-1$ cells, they were reinoculated with tumor cells in the left footpad, using $1 \times 10^{5}$ tumor cells per mouse. After the second inoculation, mice were not treated with chemotherapeutic drugs or IND. The tumor incidence referred to $21 \mathrm{~d}$ after the second transplantation.

Assay of in Vitro Sensitivity of C20 or C20/ $\beta$ A-2-1 to Chemotherapeutic Drugs Subconfluent cells were treated 
with trypsin and transferred to 24-well plates at a concentration of $1 \times 10^{5}$ cells per well. After a $24 \mathrm{~h}$ incubation at $37^{\circ} \mathrm{C}$ with $5 \% \mathrm{CO}_{2}, \mathrm{ADM}$ or CDDP was added to the culture medium at the concentration indicated, with or without $10 \mu \mathrm{M}$ IND. After a further $48 \mathrm{~h}$ incubation, the cells were treated with trypsin and counted. Student's $t$-test was used to compare unpaired means of two data sets. A value of $p<0.05$ was considered to be statistically significant.

\section{RESULTS AND DISCUSSION}

As shown in Fig. 1A, tumor growth was partially inhibited by ADM after the third administration when administered on its own. IND was effective up to two weeks after tumor inoculation. However, after two weeks, the growth rate of the tumor was almost the same as that in the controls. On the other hand, the tumor growth was markedly suppressed by the combination of IND and ADM. A similar synergistic effect was observed with the combination of IND and CDDP (Fig. 1B). We previously demonstrated that IND and BLM had a synergistic effect on in vivo C20 tumor growth in immunocompetent mice but this effect was not observed in severely combined immunodeficient mice. ${ }^{20)}$ The present results suggest that IND may act as an activator of tumor immunity in conjunction with ADM or CDDP.

MCP-1 gene transfer to $\mathrm{C} 20$ tumor cells reduced the effect of IND on in vivo tumor growth when IND was administered on its own. The inhibitory effect of ADM on C20 $\beta \mathrm{A}-$ 2-1 tumor growth was less potent than that of CDDP (Figs.

A

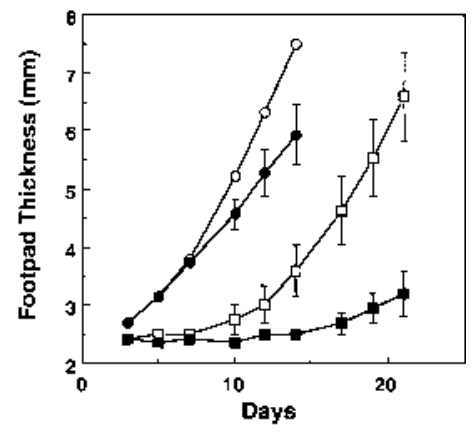

B

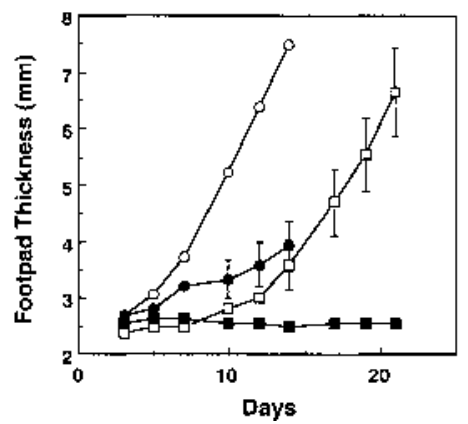

Fig. 1. Effects of Combinations of IND with ADM or CDDP on C20 Tumor Growth

$\mathrm{BALB} / \mathrm{c}$ mice were inoculated with $\mathrm{C} 20$ in the right footpad at $1 \times 10^{5}$ cells/mouse. (A) The mice were injected i.v. with $2 \mathrm{mg} / \mathrm{kg} \mathrm{ADM}$ on days $4,6,8$, and given IND via the drinking water $(0.001 \%)$ beginning on the day after tumor inoculation. $(\bigcirc), \mathrm{C} 20$

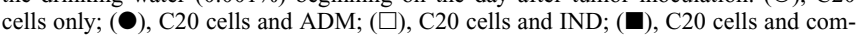
bination of ADM and IND. (B) The mice were injected i.p. with $5 \mathrm{mg} / \mathrm{kg}$ CDDP on days $4,6,8$, and given IND via the drinking water $(0.001 \%)$ beginning on the day after tumor inoculation. (O), C20 cells only; $(\bullet)$, C20 cells and CDDP; $(\square)$, C20 cells and IND; (ם), C20 cells and combination of CDDP and IND. Each point and vertical bar represent the mean \pm S.E.M.
2A, B). There was a synergistic effect of IND with ADM, although this was somewhat reduced. Strong inhibitory effects on tumor growth were observed with IND and CDDP coadministered to both $\mathrm{C} 20$ and $\mathrm{C} 20 \beta \mathrm{A}-2-1$ tumors. Our previous observation indicated that MCP-1 acted synergistically with LPS on tumor growth. ${ }^{22}$ MCP-1 gene transfer increased considerably the number of macrophages infiltrating the tumor. On the other hand, several studies have suggested that there is a correlation between tumor malignancy and MCP-1 secretion from the tumor. ${ }^{23-25)}$ Although it remains unclear whether tumor-associated macrophages can be divided into subtypes, it has been shown that the antitumor activity of macrophages is inversely correlated with the production of $\mathrm{PGE}_{2}$ and directly correlated with the production of leukotrienes. ${ }^{26)}$ Under treatment with IND, the tumor incidence rates of $\mathrm{C} 20 \beta \mathrm{A}-2-1$ were higher than those of C20 (Table 1). Thus, MCP-1 gene transfer seems to increase the malignancy of the tumor. These data could explain the reported controversial effects of IND on tumor growth. ${ }^{1-3,7-12,13-16)}$

We then examined whether IND increased the sensitivity of $\mathrm{C} 20$ and $\mathrm{C} 20 \beta \mathrm{A}-2-1$ to $\mathrm{ADM}$ or CDDP in vitro. The plasma concentrations of IND in mice, measured by HPLC, were about 3 to $6 \mu \mathrm{M}$. Therefore, we cultured $\mathrm{C} 20$ and C20 $\beta \mathrm{A}-2-1$ cells at the indicated concentration of ADM or CDDP, with or without $10 \mu \mathrm{M}$ IND. IND did not affect the dose-dependence of ADM or CDDP toxicity on both C20 and C20 $\beta$ A-2-1 (Fig. 3). There were no significant differences between the control and IND treatment. These results

A

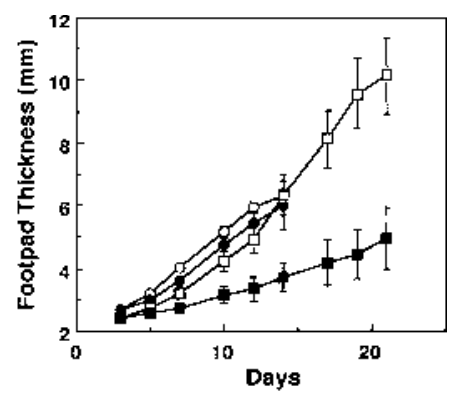

$\mathbf{B}$

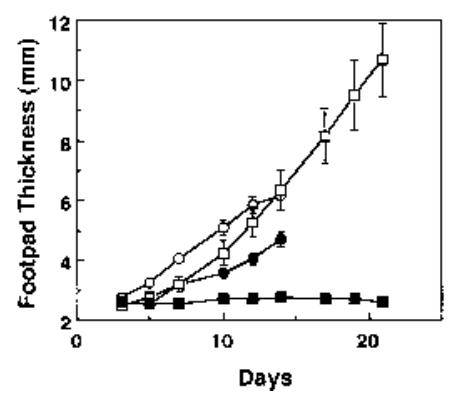

Fig. 2. Effects of Combinations of ADM or CDDP with IND on C20 $\beta$ A2-1 Tumor Growth

$\mathrm{BALB} / \mathrm{c}$ mice were inoculated with $\mathrm{C} 20 \beta \mathrm{A}-2-1$ in the right footpad at $1 \times 10^{5}$ cells/mouse. (A) The mice were injected i.v. with $2 \mathrm{mg} / \mathrm{kg}$ ADM on days $4,6,8$, and given IND via the drinking water $(0.001 \%)$ beginning on the day after tumor inoculation. (○), C20 $3 \mathrm{~A}-2-1$ cells only; $(\bullet), \mathrm{C} 20 \beta \mathrm{A}-2-1$ cells and ADM; $(\square), \mathrm{C} 20 \beta \mathrm{A}-2-1$ cells and IND; ( $\mathbf{\square})$, C20 $\beta$ A-2-1 cells and combination of ADM and IND. (B) The mice were injected i.p. with $5 \mathrm{mg} / \mathrm{kg}$ CDDP on days $4,6,8$, and given IND via the drinking water $(0.001 \%)$ beginning on the day after tumor inoculation. $(\mathrm{O}), \mathrm{C} 20 \beta \mathrm{A}-2-1$ cells

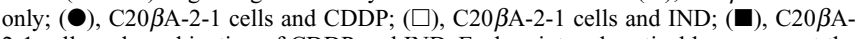
2-1 cells and combination of CDDP and IND. Each point and vertical bar represent the mean \pm S.E.M 
Table 1. Tumorigenicity of $\mathrm{C} 20$ and $\mathrm{C} 20 / \beta \mathrm{A}-2-1$ after Chemoimmunotherapy

\begin{tabular}{lccc}
\hline \hline \multirow{2}{*}{ IND } & \multicolumn{2}{c}{ Primary tumor incidence $^{a)}$} & Secondary $^{b)}$ \\
\cline { 2 - 3 } & $(-)$ & $(+)$ & $(+)$ \\
\hline $\mathrm{C} 20$ & $7 / 7$ & $9 / 9$ & - \\
$\mathrm{C} 20+\mathrm{BLM}$ & $6 / 7$ & $1 / 11$ & $3 / 10$ \\
$\mathrm{C} 20+\mathrm{ADM}$ & $7 / 8$ & $4 / 11$ & $0 / 7$ \\
$\mathrm{C} 20+\mathrm{CDDP}$ & $5 / 10$ & $1 / 11$ & $0 / 9$ \\
$\mathrm{C} 20 / \beta \mathrm{A}-2-1$ & $7 / 7$ & $8 / 9$ & - \\
$\mathrm{C} 20 / \beta \mathrm{A}-2-1+\mathrm{BLM}$ & $6 / 7$ & $5 / 10$ & $3 / 5$ \\
$\mathrm{C} 20 / \beta \mathrm{A}-2-1+\mathrm{ADM}$ & $8 / 8$ & $6 / 9$ & $1 / 3$ \\
$\mathrm{C} 20 / \beta \mathrm{A}-2-1+\mathrm{CDDP}$ & $9 / 10$ & $3 / 11$ & $0 / 8$
\end{tabular}

a) $\mathrm{BALB} / \mathrm{c}$ mice were inoculated with $\mathrm{C} 20$ or $\mathrm{C} 20 / \beta \mathrm{A}-2-1$ in the right footpad at $1 \times 10^{5} \mathrm{cells} /$ mouse. Tumor incidence (number of mice with tumor/number of mice inoculated) refers to $14 \mathrm{~d}$ (without IND) and $21 \mathrm{~d}$ (with IND) after transplantation. b) When $\mathrm{BALB} / \mathrm{c}$ mice rejected $\mathrm{C} 20$ or $\mathrm{C} 20 / \beta \mathrm{A}-2-1$, they were reinoculated with $\mathrm{C} 20$ or $\mathrm{C} 20 / \beta \mathrm{A}-2-1$ in the left footpad at $1 \times 10^{5}$ cells/mouse. Tumor incidence refers to $21 \mathrm{~d}$ after transplantation.

A

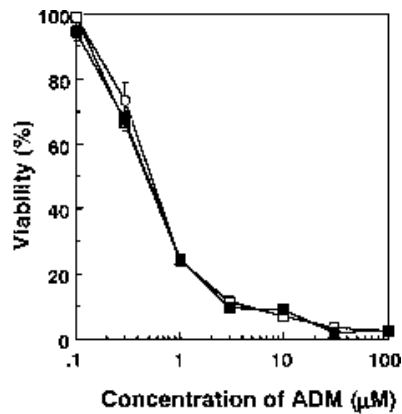

$\mathbf{B}$

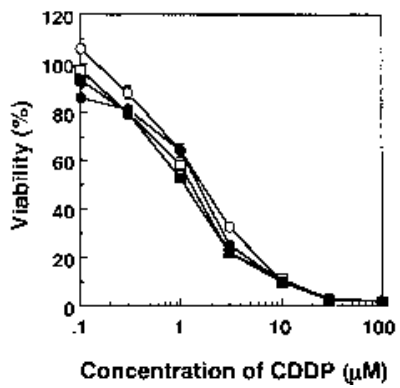

Fig. 3. Effects of IND on in Vitro Sensitivity of C20 or C20 $\beta$ A-2-1 Cells to Chemotherapeutic Agents

Cells were cultured with various concentrations of ADM (A) or CDDP (B) for $48 \mathrm{~h}$, with or without $10 \mu \mathrm{M}$ IND. (O), C20 cells with ADM (A) or CDDP (B); (O), C20 cells with IND and ADM (A) or CDDP (B); ( $\square$ ) C20 $\beta$ A-2-1 cells with ADM (A) or CDDP (B); (ם), C20 $\beta$ A-2-1 cells with IND and ADM (A) or CDDP (B). Each point indicates the mean \pm S.E.M.

suggest that the synergistic effect is not due to a direct action of IND on C20 and MCP-1 gene transfer having an effect on the sensitivities of $\mathrm{C} 20$ to ADM, CDDP and IND in vitro.

We have reported that both IND and BLM act as activators of antitumor immunity and have a strong synergistic effect. ${ }^{21)}$ Without IND, ADM or CDDP, the tumor cells were rejected by the mice that were reinoculated with tumor cells (Table 1). Antitumor immunity was also observed against MCP-1 transfectant when ADM, BLM or CDDP was administered in combination with IND.

Although the mechanism by which MCP-1 reduces the antitumor effect of IND remains unclear, several possibilities have been suggested. Firstly, it is reported that MCP-1 is in- volved in $\mathrm{T}_{\mathrm{H}} 2$ polarization. ${ }^{27)}$ Therefore, MCP-1 might suppress cellular immunity. Recently, it has also been reported that IND inhibits angiogenesis ${ }^{28}$ and MCP-1 induces it. ${ }^{29)}$ Angiogenesis might be involved in the mechanism whereby MCP-1 reduces the antitumor effect of IND. Expression of MCP-1 at the tumor site of $\mathrm{C} 20$ has also been reported. ${ }^{30)} \mathrm{Al}-$ though the amount and time-course of expression of MCP-1 was not examined, MCP-1 might be responsible to the fact that IND was effective up to two weeks but ineffective after that time.

The tumor-bearing mice were cachectic at two weeks after the tumor inoculation and a severe weight loss was observed (data not shown). IND also inhibited the weight loss of tumor-bearing mice. Tanaka et al. reported that IND inhibited the early transplant of colon 26 adenocarcinoma ${ }^{17)}$ and they also found that IND given to mice with large tumor burdens alleviated the cachexia, resulting in an increased survival time, even although the growth of the tumor had been promoted. In clinical studies, it has been reported that antiinflammatory treatment may prolong the survival of undernourished patients with metastatic solid tumors. ${ }^{31)}$ In conclusion, the combination of IND with ADM or CDDP appears to induce antitumor immunity as does the combination of BLM with IND. Thus, it may be possible that the combined administration of IND with chemotherapeutic drugs is able to prevent tumor recurrence and metastases. Although the antitumor growth effect of IND remains controversial, it is possible that IND is able to restore tumor-induced disorders in homeostasis and could be used as an adjuvant for chemotherapeutic drugs.

Acknowledgments This research was supported in part by Grants-in-Aid from the Japanese Ministry of Education, the Private School Promotion Foundation, the Uehara Memorial Foundation, and Hohansha Foundation.

\section{REFERENCES}

1) Honn K. V., Bockman R. S., Marnett L. J., Prostaglandins, 21, 833864 (1981).

2) Falton A. M., J. Natl. Cancer Inst., 78, 735-741 (1987).

3) Furuta Y., Hall E. R., Sanduja S., Barkley T., Jr., Milas L., Cancer Res., 48, 3002-3007 (1988).

4) Goodwin J. S., J. Immunopharmacol., 2, 397-424 (1980).

5) Kemp J., Louie D., Mattingly J., Bennet J., Higuchi C., Pretell J., Horowitz M., Gershon R., J. Immunopharmacol., 2, $471-489$ (1980).

6) Goodwin J. S., Ceuppens J., J. Clin. Immunol., 3, 295-315 (1983).

7) Hial V., Horakova Z., Shaff R. E., Beaven M. A., Eur. J. Pharmacol., 37, 367-376 (1976).

8) Lynch N. R., Castes M., Astoni M., Salomon J. C., Br. J. Cancer, 3, 503-512 (1978).

9) Fulton A. M., Levy J. G., Int. J. Cancer, 26, 669-673 (1980).

10) Bennet A., Berstock D. A., Carroll M. A., Br. J. Cancer, 45, 762-768 (1982).

11) Young M. R., Wheeler E., Newby M., J. Natl. Cancer Inst., 76, 745750 (1986).

12) Takahashi M., Narisawa T., Masuda T., Nagasawa O., Suzuki K., Yoshioka H., Koyama H., Jpn. J. Cancer Chemother., 14, 2334-2340 (1987) in Japanese.

13) Plescia O. J., Smith A. H., Grinwich K., Proc. Natl. Acad. Sci. U.S.A., 72, 1848-1851 (1975).

14) Favalli C., Garaci E., Etheredge E., Santoro M. G., Jafe B. M., J. Immunol., 125, 897-902 (1980).

15) Hofer D., Dubitsky A. M., Reilly P., Santoro M. G., Jaffe B. M., Prostaglandins, 20, 1033-1038 (1980).

16) Feldman J. M., Hilf R., J. Natl. Cancer Inst., 75, 751—756 (1985). 
17) Tanaka Y., Tanaka T., Ishitsuka H., Cancer Res., 49, 5935-5939 (1989).

18) Jimbo T., Akimoto T., Tohgo A., Cancer Immunol. Immunother., 40, 10-16 (1995).

19) Nakata K., Kashimoto S., Yoshida H., Oku T., Nakamura S., Cancer Res., 48, 584-588 (1988).

20) Teicher B. A., Korbut T. T., Menon K., Holden S. A., Ara G., Cancer Chemoter. Pharmacol., 33, 515-522 (1994).

21) Matsushita R., Hattori K., Hayashi K., Iizasa H., Ichimura F., Nakashima E., Pharmaceutical Res., 18, 243-245 (2001).

22) Nakashima E., Kubota Y., Matsushita R., Ozaki E., Ichimura F., Kawahara S., Nakanishi I., Kuno K., Matsushima K., Pharmaceutical Res., 15, 685-689 (1998).

23) Neumark E., Anavi R., Witz I. P., Ben-Baruch A., Immunol. Lett., 68, $141-146$ (1999).

24) Amann B., Perabo F. G., Wirger A., Hugenschmidt H., Schultze-Seemann W., Br. J. Urol., 82, 118-121 (1998).
25) Takeshima H., Kuratsu J., Takeya M., Yoshimura T., Ushio Y., J. Neurosurg., 80, 1056-1062 (1994).

26) Ben-Efraim S., Bonta I. L., Int. J. Immunopharmac., 16, 397-399 (1994).

27) Gu L., Tseng S., Horner R. M., Tam C., Loda M., Rollins B. J., Nature (London), 404, 407-411 (2000).

28) Jones M. K., Wang H., Peskar B. M., Levin E., Itani R. M., Sarfeh I. J., Tarnawski A. S., Nature Med., 5, 1418-1423 (1999).

29) Salcedo R., Ponce M. L., Young H. A., Wasserman K., Ward J. M., Kleinman H. K., Oppenheim J. J., Murphy W. J., Blood, 96, 34-40 (2000).

30) Yasumoto K., Mukaida N., Harada A., Kuno K., Akiyama M., Nakashima E., Fujioka N., Mai M., Kasahara T., Fujimoto-Ouchi K., Mori K., Tanaka Y., Matsushima K., Cancer Res., 55, 921-927 (1995).

31) Lundholm K., Gelin J., Hyltander A., Leonnroth C., Sandstreom R., Svaninger G., Cancer Res., 54, 5602-5606 (1994). 